\title{
LAS PAREMIAS DE LA CRÓNICA TROYANA PROMOVIDA POR ALFONSO ONCENO (1312-1350) EN SU CONTEXTO FILOLÓGICO: INESTABILIDAD, RITMO Y FIJEZA*
}

\author{
Francisco Pedro Pla Colomer \\ fpla@ujaen.es \\ Universidad de Jaén
}

\section{INTRODUCCIÓN E HIPÓTESIS DE PARTIDA}

Esta investigación tiene como finalidad el estudio filológico de la Crónica troyana promovida por Alfonso Onceno (datada hacia 1350), a partir de una aproximación fonético-fonológica contrastiva, fraseológica y, de manera más detallada, paremiológica. A partir del estudio del corpus variacional de refranes se pretende extraer datos significativos conducentes a delimitar los patrones constitutivos que han dado lugar al proceso de fijación de estas estructuras, en el marco teórico de los estudios de Anscombre ${ }^{1}$, Bizzarri ${ }^{2} \mathrm{u} \mathrm{Oddo}^{3}$, entre otros.

La obra que aquí nos ocupa se inserta en el ámbito de recepción de las translaciones peninsulares del Roman de Troie, en estrecha relación con el proceso compositivo de la Historia troyana polimétrica y la Cronica Troiana gallega. No han sido muchos los investigadores que han centrado el punto de atención en esta obra; de entre ellos destacan los estudios precursores de Menéndez Pidal ${ }^{4}$, junto a los más innovadores de Lorenzo ${ }^{5}$, Casas $^{6}$ y la tesis doctoral llevada a cabo por

* Este trabajo se inscribe en el proyecto Historia e historiografía de la lengua castellana en su diacronía contrastiva (HISLECDIAC) con referencia FFI2017-83688-P, financiado por la Agencia Estatal de Investigación (AEI) y el Fondo Europeo de Desarrollo Regional (FEDER) y gestionado por la Universidad de Valencia a través del Departamento de Filología Española. El proyecto forma parte del Programa Estatal de Fomento de la Investigación Científica y Técnica de Excelencia, Subprograma Estatal de Generación de Conocimiento y está dirigido por la Dra. María Teresa Echenique Elizondo y la Dra. María José Martínez Alcalde.

${ }^{1}$ Jean-Claude Anscombre, «Estructura métrica y función semántica de los refranes», $P a$ remia, 8 (1999), pp. 25-36.

${ }^{2}$ Hugo O. Bizzarri, El refranero castellano en la Edad Media, Madrid, Laberinto, 2004.

${ }^{3}$ Alexandra Oddo, «Historia de una pareja inseparable: el ritmo en el refranero español», Rhythmica, 13 (2015), pp. 173-192.

${ }^{4}$ Anónimo, Historia troyana en prosa y verso, Ramón Menéndez Pidal (ed.), Textos medievales españoles. Obras completas de Ramón Menéndez Pidal, XII, Madrid, Espasa-Calpe, 1976.

${ }^{5}$ Anónimo, Cronica troiana, Ramón Lorenzo (ed.), A Coruña, Real Academia GalegaFundación Barrié, 1985.

${ }^{6}$ Juan Casas Rigall, La materia de Troya en las letras romances del siglo XIII hispano, Santiago de Compostela, Servicio de Publicacións da Universidade de Santiago de Compostela, 1999. 
D'Ambruoso ${ }^{7}$. Por ello, se hace necesario, en primer lugar, un estudio de carácter filológico que tenga como objeto el análisis fonético-fonológico contrastivo con textos coetáneos como el Libro de Buen Amor, con la finalidad de datar con mayor precisión el proceso compositivo de este texto; además, en segundo lugar, se ofrece un análisis de los usos fraseológicos empleados desde una perspectiva fraseométrica, en la línea metodológica marcada por Lapesa ${ }^{8}$, Echenique y Echenique, Martínez y Sánchez ${ }^{10}$, insertos en el marco filológico integral, y complementados, a su vez, por otras investigaciones.

\section{La CRónica troyana PROMOVIDA POR Alfonso OnCENo (CA. 1350)}

La Crónica troyana se conserva en cuatro manuscritos: $A$ (H.I.6, Biblioteca de San Lorenzo del Escorial) es el único que contiene la obra completa, datado en 1388 , se compuso entre finales del reinado de Alfonso Onceno (1312-1350) y comienzos del de Pedro I (13501369); la primera parte de $M$ (10146, Biblioteca Nacional de España) se remonta a mediados del s. XIV $(M a)$ y su segunda parte data del siglo Xv ( $M b)$; en tanto que $M^{\prime}$ (L.II.16, Biblioteca de San Lorenzo del Escorial) y $B$ (M-558, Biblioteca Menéndez Pelayo) son de finales del XIV.

Todavía no se conoce con precisión la filiación de los manuscritos, en tanto hay teorías que defienden una primera traducción gallega del poema francés ${ }^{11}$, de la que derivan las ramas castellanas, al tiempo que, desde el estudio de Menéndez Pidal ${ }^{12}$, se postula la existencia de una traducción intermedia en leonés, eslabón que permitiría justificar la pervivencia de leonesismos, o soluciones occidentales, constatadas en los manuscritos, tales como casos de diptongación secundaria, así como la no diptongación de vocales breves tónicas latinas.

\footnotetext{
${ }^{7}$ Claudia D’Ambruoso, Edición crítica y estudio de la Crónica troyana promovida por Alfonso XI, tesis doctoral inédita dirigida por Juan Casas Rigall, Santiago de Compostela, Universidade de Santiago de Compostela, 2012. Agradezco su cordialidad por la consulta de sus materiales todavía inéditos, de donde se extraen los ejemplos.

${ }^{8}$ Rafael Lapesa Melgar, «Alma y ánima en el Diccionario histórico de la lengua española: su fraseología», en Léxico e Historia, II. Diccionarios, Madrid, Istmo, 1992, pp. 79-86.

${ }^{9} \mathrm{M}$. ${ }^{\mathrm{a}}$ Teresa Echenique Elizondo, «Pautas para el estudio histórico de las unidades fraseológicas», en José Luis Girón Alconchel, Silvia Iglesias Recuero, Francisco Javier Herrero Ruiz de Loizaga y Antonio Narbona Jiménez (coords.), Estudios ofrecidos al profesor José Jesús de Bustos Tovar, t. I, Madrid, Universidad Complutense, 2003, pp. 545-560.

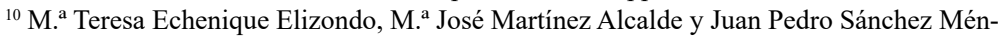
dez, «Perspectivas en el estudio diacrónico de la fraseología en su amplitud hispánica (peninsular, insular y americana)», en M. ${ }^{a}$ Teresa Echenique Elizondo, M. ${ }^{a}$ José Martínez Alcalde, Juan Pedro Sánchez Méndez y Francisco Pedro Pla Colomer (eds.), Fraseología española: diacronía y codificación, Madrid, CSIC (Anejos de la Revista de Filología Española), 2016, pp. 17-32.

${ }^{11}$ Ramón Lorenzo (ed. cit.), frente a estas posturas, barajó la hipótesis de que quizás el modelo de la Crónica troyana no fuera el Roman de Troie, sino una de sus cinco prosificaciones francesas.

${ }^{12}$ Ramón Menéndez Pidal, ed. cit.
} 


\subsection{Breve análisis filológico del texto}

El estudio de la métrica y la rima de los textos poéticos permite desentrañar la oralidad subyacente en la materialidad textual de los testimonios conservados, tal como se ha constatado en anteriores publicaciones ${ }^{13}$. A partir de una selección significativa de los rasgos caracterizadores del Libro de Buen Amor ${ }^{14}$ se pretende contrastar el componente fónico de la Crónica troyana y, de esta manera, concretar su período de elaboración.

2.1.1. A pesar de que la pérdida de vocal final de palabra tras consonante distinta a [r], [s], [1], [n], [d], [ts] represente en la oralidad un rasgo en desuso, la métrica del verso $671 \mathrm{c}$ atestigua la forma apocopada de <nief>, documentada en el ms. G: estades enfriada más que nief' de la sierra (671c) < NĚVE (oóo òoóo / òoó òoóo).

La documentación de esta forma en diversos textos coetáneos es indicio de que no puede circunscribirse únicamente al registro de una obra determinada. No resulta casual, a todas luces, el mantenimiento de esta misma variante $(<$ nief $>$ ) en el ms. $A$ de la Crónica troyana, testimonio datado hacia finales del reinado de Alfonso Onceno: Después d'esto embraçó un escudo blanco como una nief e todo orellado de rubis (p. 1140).

2.1.2. Los textos poéticos del período que abarca los reinados de Fernando III (1217-1252) a Sancho IV (1284-1295) presentan en sus rimas regularidad articulatoria del sufijo [-jé.Ko]. Es precisamente entre el reinado de Fernando IV (1295-1312) y Alfonso Onceno (1312-1350) el momento en que se documenta la apertura del proceso de monoptongación. En convivencia con esta variante, la obra juanruiciana documenta el mantenimiento de la forma minoritaria [-jé.Ko], justificada en la rima 314 entre <poquiello, colmiello, noviello y sello>.

La convivencia de variantes condujo al empleo distribucional en una misma obra según imperativos de la rima, así como fue aprovechada para la recreación de verosimilitud lingüística. En el caso de la Crónica troyana, el mantenimiento de formas sin monoptongar, documentadas en $A$, apunta a un primer estadio compositivo

${ }^{13}$ Francisco Pedro Pla Colomer, Métrica, rima y oralidad en el Libro de Buen Amor, Valencia, Quaderns de Filologia, 2012; Letra y voz de los poetas en la Edad Media castellana. Estudio filológico integral, Valencia-Neuchâtel, Tirant Humanidades-Université de Neuchâtel, 2014; «Métrica y pronunciación en el Libro de Buen Amor: prototipo del isosilabismo castellano medieval», Analecta Malacitana, 38 (2015), pp. 55-78; «Fraseología y métrica en el Libro de Buen Amor», en Actas del V Congreso Internacional Juan Ruiz, Arcipreste de Hita y el Libro de Buen Amor, Alcalá la Real, Ayuntamiento de Alcalá la Real, 2017, pp. 327-334.

${ }^{14}$ Cito todos los ejemplos del Libro de Buen Amor siguiendo la edición de Juan Corominas (Libro de Buen Amor, Madrid, Gredos, 1967), siempre cotejando los manuscritos y el resto de ediciones. 
coincidente con el del Libro de Buen Amor: Después diole un aniello de oro con su piedra muy preçiosa e más fermosa de cuantas vi (pp. 35-36. $A$ : <aniello $>$; $B$ : $<$ anjllo $>$ ).

La preferencia por la forma con diptongo de $A$, frente a la presencia mayoritaria del resultado monoptongado en los otros testimonios, encuentra correspondencia con los resultados que se extraen del estudio de las rimas de los textos poéticos situados en un eje diacrónico: de la variabilidad de formas a las que recurre Juan Ruiz, presentes en el habla viva, a la fijación y preferencia por la variante monoptongada en textos poéticos como los de Sem Tob, Pero López de Ayala o la poesía de cancionero.

2.1.3. En el Libro de Buen Amor se documenta la generalización de la forma con hiato del pretérito imperfecto, aunque todavía en convivencia con la forma diptongada, como ponen de manifiesto las rimas de sus estrofas, complementadas por los testimonios gráficos de $S$ y $G$.

Los testimonios $A$ y $M b$ de la Crónica troyana presentan una clara tendencia al empleo de la variante con hiato, en tanto $B$ mantiene la grafia que representaba, de forma genérica, la variante tautosilábica: del primero palaçio fasta el postremero, avía bien diez moradas ( $\mathrm{p}$. 225. $A$ y $M b$ : <avia $>$; $B$ : <auie>); por algunas cosas que tenía de fablar con él (p. 276. A y Mb: $<$ tenia $>$; $B$ : $<$ tenie $>$ ); E alli fallaron dos reyes que yazían muertos entre los otros (p. 647. A y $M b$ : <yazian>; $B:<$ yazien $>$ ).

La lectio de $A$ de la Crónica troyana es la más adecuada a los patrones lingüísticos de la época de Alfonso Onceno, si bien es cierto que deben mantenerse las variantes alomórficas documentadas en el mismo, ya que desde la generalización de la variante con diptongo [jé], corroborada a partir de la métrica de los textos de Berceo y el Libro de Alexandre, hasta la consolidación articulatoria del hiato en época de los Reyes Católicos, el reinado de Alfonso Onceno representa la etapa donde tiene lugar la regularización de las estructuras silábicas, todavía en contienda con formas arcaicas de reinados anteriores ${ }^{15}$.

De manera complementaria, datar el proceso de producción de la Crónica troyana entre los años 30 y 40 hasta el final del reinado de Alfonso Onceno no contradice el colofón de $A$, en tanto «fue acabado de escrivir e de estoriar» en el reinado de Pedro I puede hacer referencia a un último período compositivo del manuscrito:

${ }^{15}$ En el Rimado de Palacio las formas de pretérito imperfecto se articulan, en posición de rima, con hiato [í.a], en tanto que en interior de verso la contienda de variantes es consecuencia de la intención de Ayala por regularizar sus versos. En el Cancionero de Baena todavía se confirman ciertas variantes en desuso del pretérito imperfecto con diptongo. A partir de dicho momento, los imperfectos de indicativo empezaron a regularizarse en el paradigma verbal, influidos, fonéticamente, por la adaptación y la acomodación de los diptongos e hiatos en la lengua. Este fenómeno llevó consigo la progresiva desaparición de las variantes [-í.e] e [-já], que llegaron como residuos hasta los reinados de Juan I y Enrique III el Doliente. 
Este libro mandó fazer el muy alto e muy noble e muy exçellente rey don Alfonso [...]. E fue acabado de escrivir e de estoriar en el tiempo que el muy noble rey don Pedro, su fijo, regnó [...]. Fecho el libro postremero día de deziembre, era de mill e treçientos e ochenta e ocho años.

Nicolás Gonçález escrivan de los sus libros lo escriví por su mandado. (Crónica troyana, p. 1513)

Son precisamente los rasgos lingüísticos y una estilística textual más viva lo que aleja la Crónica troyana de la Historia troyana polimétrica, y las ubica en dos momentos cronológicos diferentes: una de finales del siglo XIII, otra perteneciente al proyecto de Alfonso Onceno, datos, todos ellos, que corroboran la datación propuesta por Menéndez Pida ${ }^{16}$ para la Historia troyana polimétrica (c. 1270), recientemente defendida por Gómez Redondo ${ }^{17}$.

\section{ANÁlisis PAREMIOLÓGiCo DESDE LA PERSPECTIVA DE UNA TEORÍA FRASEOMÉTRICA}

En estudios anteriores se ha constatado ( $\mathrm{Pla}^{18}$; Pla y Vicente ${ }^{19}$, desde una perspectiva fraseométrica, que en el proceso de fijación de las locuciones influyeron ciertos patrones rítmicos de la lengua, en tanto la noción de ritmo no se circunscribe únicamente al campo de la poesía, sino a la totalidad de la producción del lenguaje. Desde este presupuesto, es necesaria la aplicación sistemática de estos resultados, si bien parciales, al campo de la paremiología ${ }^{20}$, en

\footnotetext{
${ }^{16}$ Ramón Menéndez Pidal, ed. cit.

${ }^{17}$ Fernando Gómez Redondo, «Poemas noticieros e historiográficos: siglos XIII-XIV», en Fernando Gómez Redondo (coord.), Historia de la métrica medieval castellana, San Millán de la Cogolla, Cilengua, 2016, pp. 185-207. Desde este punto de vista, no coincido con la tesis expuesta por Nuria Larrea («La Historia troyana polimétrica y el Poema de Alfonso XI, ¿dos obras de un mismo taller?», Epos: Revista de filología, 28 (2012), pp. 91-105), para quien la Historia troyana polimétrica y el Poema de Alfonso Onceno podrían haber pertenecido al mismo scriptorium de la corte de Alfonso Onceno. Los rasgos lingüísticos expuestos en este trabajo conducen a una datación más temprana de la obra polimétrica. En un futuro estudio se abordarán los aspectos fraseológicos en contraste con los documentados en el Libro de Buen Amor.

${ }^{18}$ Francisco Pedro Pla Colomer, «Aproximación a una fraseometría histórica de la lengua castellana: el Libro de miseria de omne y el segundo ciclo del mester de clerezía», en M. ${ }^{\mathrm{a}} \mathrm{Te}-$

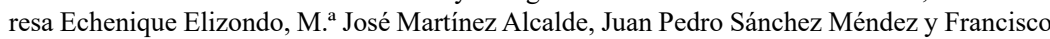
Pedro Pla Colomer (eds.), Fraseología española: diacronía y codificación, op. cit., pp. 59-74; «Fundamentos para una fraseometría histórica del español», Rhythmica, 15 (2017), pp. 87-112.

${ }^{19}$ Francisco Pedro Pla Colomer y Santiago Vicente Llavata, «Aproximación a una fraseología contrastiva en los textos peninsulares de materia troyana: el Libro de Alexandre, la Historia troyana polimétrica y la Crónica troyana de Juan Fernández de Heredia», en M. ${ }^{2}$ Teresa Echenique Elizondo, M. ${ }^{a}$ José Martínez Alcalde (eds.) y Francisco Pedro Pla Colomer (coord.), La fraseología a través de la historia de la lengua española y su historiografia, Valencia-Neuchâtel, Tirant Humanidades, 2017, pp. 113-155.

${ }^{20}$ Complementado con estudios como los de Margit Frenk, «Refranes cantados y cantares proverbializados», Nueva revista de Filología Hispánica, 15 (1961), pp. 155-168; «La compleja relación entre refranes y cantares antiguos», Paremia, 6 (1997), pp. 235-244.
} 
tanto estructuras complejas sujetas a parámetros constitutivos estrechamente vinculados con la mnemotecnia (tales como el ritmo, la rima, repetición de sonidos, etc. ${ }^{21}$ ) que desencadenaron el proceso de fijación y generalización de las mismas. Para este caso, se ha fijado un corpus de las siete paremias documentadas en la Crónica troyana promovida por Alfonso Onceno, con la finalidad de llevar un estudio de carácter diacrónico de cada una de ellas y evidenciar la existencia de dichos patrones constitutivos.

Las paremias que la versión castellana documenta son originales $\left(\right.$ Lorenzo $\left.{ }^{22}\right)$; aunque recientes estudios señalan que dos de ellas (/Muy loco es a quien el loco tresquila ${ }^{23} \mathrm{y}$ lel amigo siempre se prueba en la coita/) coinciden con la fuente francesa (Casas ${ }^{24}$ y D' Ambruoso $^{25}$ ).

La aparición de un número elevado de paremias en la Crónica troyana, que no encuentran correspondencia explícita o directa en el poema francés, ha suscitado el interés de los investigadores que han abordado el estudio de esta obra. Casas ${ }^{26}$ constata la coincidencia absoluta que se da en el empleo de tres paremias entre esta obra (/de los escarmentados se fazen los arteros/, /Mal de muchos confuerto es/ y / Faz bien e non cates a quien/) y la Historia troyana polimétrica, dato recurrente que permite confirmar la existencia de una fuente intermedia común de la que partieron las dos traducciones castellanas ${ }^{27}$.

\subsection{Estructuras fluctuantes en proceso de fijación}

3.1.1. La inestabilidad métrica de esta estructura/me entra por la una oreja e me sale por la otra/ (p. 963, óo oó oóo / óo óo óo óo) viene confirmada por períodos arrítmicos de troqueos y dáctilos, cuya regularización irá de la mano de la evolución de la lengua castellana.

${ }^{21}$ Un esbozo sobre una gramática de los refranes se puede encontrar en el estudio introductorio de Hugo O. Bizzarri (López de Mendoza, Íñigo, Refranes que dizen las viejas tras el fuego, ed. de Hugo O. Bizzarri, Kassel, Reichenberger, 1995).

${ }^{22}$ Ramón Lorenzo, ed. cit. «Benoît non utiliza no seu poema proverbios, en cambio o traductor español non puido fuxir á tentación de utiliza-lo refraneiro popular, pagando así tributo á moda de toda a literatura medieval peninsular» (p. 51).

${ }^{23}$ El ámbito de la locura era recurrente en las paremias, como así lo registra la obra anónima del siglo XVI (Anónimo, Refranes famosissimos y prouechosos glosados, Hugo O. Bizzarri (ed.), Lausanne, Hispanica Helvetica, 2009): Lo que haze el loco a la darreria, haze el sabio a la postrimeria.

${ }^{24}$ Juan Casas Rigall, op. cit.

${ }^{25}$ Claudia D'Ambruoso, op. cit.

${ }^{26}$ Juan Casas Rigall, op. cit.

${ }^{27}$ En Francisco Pedro Pla Colomer y Santiago Vicente Llavata, «Sobre fraseología y fraseometría históricas: la materia troyana en las tradiciones textuales medievales iberorromances», en M. ${ }^{\text {a }}$ Teresa Echenique Elizondo, Angela Schrott y Francisco Pedro Pla Colomer (eds.), Cómo se hacen las unidades fraseológicas: continuidad y renovación en la diacronía del espacio castellano, Bern, Peter Lang, 2018, pp. 29-54, se defiende la impronta ejercida por la Historia troyana polimétrica en el proceso compositivo de la Crónica troyana, a partir de un estudio lingüístico-contrastivo, sin necesidad de aludir a una traducción intermedia entre el poema francés y las obras peninsulares. Este dato se vería reforzado por la coincidencia en el uso coincidente de estructuras fijas, tales como los refranes aludidos. 
La pérdida del determinante en esta variante desautomatizada confirma el punto intermedio en la historia de este refrán. Todavía mantiene el orden gramatical esperable [sujeto + verbo + complementos], por lo que habría que suponer un cambio del tipo: me entra por la una oreja > me entra por una oreja, que abarcaría todo el período medieval hasta el siglo XviII. Así lo recoge Juan de Mal Lara ${ }^{28}$ (1568), en tanto Hernán Núñez ${ }^{29}$ (1555) documenta una variante motivada por un proceso de desautomatización. Correas $^{30}$ (1627), por su parte, hace acopio de dos estructuras en convivencia que han perdurado hasta la actualidad:

\begin{tabular}{|l|l|l|}
\hline Datación & \multicolumn{1}{|c|}{ Variante de la paremia } & \multicolumn{1}{|c|}{ Escansión métrica } \\
\hline 1555 & $\begin{array}{l}\text { Mi hija blanca y bermeja, por la boca le } \\
\text { entra, que no por el oreja (Hernán Núñez, } \\
\text { Refranes o proverbios en romance) }\end{array}$ & oóo oóo oóo / óo óo óo / oó \\
\hline 1568 & $\begin{array}{l}\text { por una oreja me entra e por otra me sale } \\
\text { (Juan de Mal Lara, Philosophia vulgar) }\end{array}$ & oóo óo óo / óo óo oóo \\
\hline \multirow{2}{*}{1627} & $\begin{array}{l}\text { 966. /Por un oído le entra, y por otro le le oóo óo / óo óo oóo } \\
\text { sale/ (Gonzalo Correas, Vocabulario de } \\
\text { refranes y frases proverbiales) }\end{array}$ & oó \\
\cline { 2 - 3 } & $\begin{array}{l}\text { 968 / Por una oreja le entra, y por otra le } \\
\text { sale/ (Gonzalo Correas, Vocabulario de } \\
\text { refranes y frases proverbiales) }\end{array}$ & oóo óo óo / óo óo oóo \\
\hline
\end{tabular}

La variación sufrida desde la primera documentación de esta paremia en la obra promovida por Alfonso Onceno encuentra fundamento en la regularización del sistema métrico-rítmico de sus constituyentes, esto es, en dos miembros heptasílabos de ritmo trocaico.

La tendencia de las paremias a constituirse en periodos rítmicos predominantemente estables habría sido la razón conducente a la permuta de los componentes gramaticales, con la finalidad de fijar un período rítmicamente regular que perdura en la actualidad:

\begin{tabular}{|c|c|}
\hline \multicolumn{1}{|c|}{ Paremia } & Escansión métrica \\
\hline Por una oreja me entra y por la otra me sale & oóo óo óo / óo óo oóo \\
\hline
\end{tabular}

\footnotetext{
${ }^{28}$ Juan de Mal Lara, La Philosophia vulgar, Inoria Pepe Sarno y José-María Reyes Cano (eds.), Madrid, Cátedra, 2013.

${ }^{29}$ Hernán Núñez, Refranes o proverbios en romance, Salamanca, Casa de Iuan de Canou, 1555 (Facsímil: <http://www.cervantesvirtual.com/obra/refranes-o-proverbios-en-romance/>).

${ }^{30}$ Gonzalo Correas, Vocabulario de refranes y frases proverbiales, Louis Combet (ed.), Bordeaux, Institut d'Études Ibériques et Ibéro-Americaines, 1967; Vocabulario de refranes y frases proverbiales, Louis Combet, Robert James y Maïte Mir-Andreu (eds.), Madrid, Castalia, 2000.

${ }^{31} \mathrm{Se}$ constata el alto grado de vitalidad de esta paremia en variantes como /por una oreja me entra y por otra me sale/ ([o] óo óo óo / [o] oóo oóo), /me entra por una oreja y me sale por la otra/ (óo oóo óo / ooóo ooóo), lentra por un oido y sale por otro/ (óo oó oóo / oóo oóo), /por un oído me entra y por otro me sale/ (oó oó oóo / [o] oóo oóo), etc. Todas ellas tienen en común la tendencia a la isometría de hemistiquios heptasílabos isorrítmicos.
} 
3.1.2. En el caso de /Mal de muchos confuerto es/, la lectio del manuscrito $A$ de la Crónica troyana se ve complementada por la variante que ofrece el testimonio $M^{\prime}$ /Mal de muchos gozo es/:

\begin{tabular}{|l|l|}
\hline Crónica troyana & Escansión métrica \\
\hline $\begin{array}{l}\text { e porque diz el proverbio: Mal de muchos confuerto es } \\
\text { (p. } 627 ; \mathrm{ms} \text {. A) }\end{array}$ & óo óo / oó oó \\
\hline e porque diz el proverbio: Mal de muchos gozo es (ms. $M^{\prime}$ ) & óo óo / òoó \\
\hline
\end{tabular}

El contraste con otros textos ${ }^{32}$ permite confirmar que la variante mayoritaria es la que presenta el significado de 'alegría que provoca el mal ajeno', a través del empleo de voces léxicas que se corresponden con el mismo campo semántico: alegría, gozo; en contraste con la forma que implica un significado de 'consuelo que provoca el mal ajeno', como se desprende del significado de consuelo y conorte:

\begin{tabular}{|l|l|l|}
\hline Datación & \multicolumn{1}{|c|}{ Variante de la paremia } & Escansión métrica \\
\hline $1300-1305$ & $\begin{array}{l}\text { E por ende dizen que mal de muchos alegría es } \\
\text { (Libro del cavallero Çifar) }\end{array}$ & óo óo / ooó oó \\
\hline 1438 & $\begin{array}{l}\text { mal de muchos gozo es (Alfonso Martínez, } \\
\text { Corbacho) }\end{array}$ & óo óo / òoó \\
\hline 1534 & $\begin{array}{l}\text { mal de muchos sea gozo (Feliciano de Silva, } \\
\text { Segunda Celestina) }\end{array}$ & óo óo /óo óo \\
\hline 1536 & $\begin{array}{l}\text { mal de muchos consuelo es (Gaspar Gómez de } \\
\text { Toledo, Tercera parte de la tragicomedia de } \\
\text { Celestina) }\end{array}$ & óo óo /oó oó \\
\hline 1541 & $\begin{array}{l}\text { mal de muchos: conorte es (Refranes glosados) } \\
\text { oal de muchos, gozo es (Hernán Núnez, Refranes } \\
\text { oprovios en romance) }\end{array}$ & óo óo óo / oó oó \\
\hline 1555 & $\begin{array}{l}\text { mal de muchos, gozo es (Mateo Luján de Saavedra, } \\
\text { Segunda parte de la vida del pícaro Guzmán de óo / òoó } \\
\text { Alfarache) }\end{array}$ & ó \\
\hline 1603 & $\begin{array}{l}\text { mal de muchos es gozo (Agustín de Rojas, El viaje } \\
\text { entretenido, 1603) }\end{array}$ & óo óo / óóo \\
\hline 1627 & $\begin{array}{l}\text { Mal de muchos, gozo es. } \\
\text { Mal de muchos, conhorto es (Gonzalo Correas, } \\
\text { Vocabulario de refranes y frases proverbiales) }\end{array}$ & óo óo / oó oó \\
\hline
\end{tabular}

La documentación de estos datos sorprende desde una perspectiva métrica, en tanto la paremia con la voz gozo se caracteriza por una asimetría, en contraste con la que presenta consuelo o conorte. Ambas formas son isorrítmicas, por lo que su larga pervivencia desde el medioevo hasta el siglo XvIII se justifica por la cadencia ágil que proporciona la concatenación de troqueos. No obstante, la métrica regular que presenta mal de muchos conorte/consuelo es (óo óo / oó

${ }^{32}$ Consultado en la base de datos CORDE [en línea, s.v. MAL DE MUCHOS], Corpus diacrónico del español, enlace: <http://www.rae.es> [consulta: 8/06/2017]). 
oó) fue uno de los motivos por los que se constituyó como variante preferente por los hablantes que ha pervivido hasta nuestros días en la forma mal de muchos, consuelo de tontos ${ }^{33}$.

3.1.3. Desde el siglo XIV se constata la pervivencia de múltiples variantes de /suele arder el justo por el pecador/ (p. 950, óo óo óo / oó ooó) que se reparten en dos posibilidades gramaticales opuestas: singular / plural, todas ellas encabezadas por una pluralidad de formas que comparten el ámbito semántico del castigo: /lazrar, pagar o arder/:

\begin{tabular}{|c|c|c|}
\hline & Variante en plural & Variante en singular \\
\hline \multirow[t]{2}{*}{ Siglo XIV } & $\begin{array}{l}\text { lazren justos por pecadores (s. XIV, } \\
\text { Anónimo, Libro del caballero Çifar) }\end{array}$ & \multirow{2}{*}{$\begin{array}{l}\text { E por tal fecho como este } \\
\text { oí dezir que suele arder el } \\
\text { justo por el pecador (c. } 1350, \\
\text { Crónica troyana, p. } 950)\end{array}$} \\
\hline & $\begin{array}{l}\text { lastran justos por pecadores } \\
\text { (c. 1330-1343, Juan Ruiz, Libro de Buen } \\
\text { Amor, 667a) }\end{array}$ & \\
\hline \multirow[t]{3}{*}{ Siglo XV } & $\begin{array}{l}\text { e non penen justos por pecadores (c. } \\
\text { 1449, Fernando de la Torre, Libro de las } \\
\text { veynte cartas e quistiones) }\end{array}$ & \multirow{3}{*}{$\begin{array}{l}\text { Arder verde por seco y lazera } \\
\text { justo por pecador }{ }^{34}(\mathrm{~s} . \mathrm{xv}, \\
\text { Marqués de Santillana, } \\
\text { Refranes que dizen las viejas } \\
\left.\text { tras el fuego, } \mathrm{n}^{\circ} 58\right)\end{array}$} \\
\hline & $\begin{array}{l}\text { Lazran justos por pecadores (c. } 1450, \\
\text { Seniloquium, } \mathrm{n}^{\circ} 225 \text { ) }\end{array}$ & \\
\hline & $\begin{array}{l}\text { No paguen justos por pecadores (c. } \\
\text { 1499-1503, La Celestina, auct. 4) }\end{array}$ & \\
\hline \multirow[t]{3}{*}{$\begin{array}{l}\text { Siglos } \\
\text { XVI-XVII }\end{array}$} & $\begin{array}{l}\text { paguen los justos por los pecadores (s. } \\
\text { XVI, Anónimo, Refranes famosissimos y } \\
\text { prouechosos glosados, p. 295) }\end{array}$ & \multirow{2}{*}{$\begin{array}{l}\text { Alius peccat, alius plectitur, } \\
\text { peca el uno, y es castigado } \\
\text { otro, lo que dezimos paga } \\
\text { justo por pecador (1615, } \\
\text { Diego López, Declaración } \\
\text { magistral sobre las [sic] } \\
\text { emblemas de Andrés Alciato) }\end{array}$} \\
\hline & $\begin{array}{l}\text { pagar justos por pecadores. } \\
\text { (1600, Francisco de Quevedo, } \\
\text { Pregmática que este año } 1600 \text { se } \\
\text { ordenó) }\end{array}$ & \\
\hline & $\begin{array}{l}\text { Lacera el justo por el pecador } \\
\text { (1627, Gonzalo Correas, Vocabulario de } \\
\text { refranes y frases proverbiales) }\end{array}$ & $\begin{array}{l}\text { Lo que puyan justos por } \\
\text { pecadores }(1627, \text { Gonzalo } \\
\text { Correas, Vocabulario } \\
\text { de refranes y frases } \\
\text { proverbiales })\end{array}$ \\
\hline
\end{tabular}

${ }^{33}$ En este caso, la primera documentación / consuelo de tontos/ la ofrece Baltasar Gracián en El Criticón. Las bases de datos electrónicas no ofrecen testimonios anteriores al siglo XVII. Esto no significa que esta forma no hubiera gozado de una vida continuada en forma latente en el habla más popular, motivada por la creación de una suerte de rima que, en aras de ganar eficacia en el proceso mnemotécnico, rompió la regularidad métrica de los dos miembros de la paremia.

${ }^{34}$ No resulta casual la coincidencia entre esta variante y la de la Crónica troyana. La forma que recoge el Marqués de Santillana consta de dos miembros: arder verde por seco / lazrar justo por pecador, estructura compuesta que recoge Hernán Núñez (Arde verde por seco y pagan justos por peccadores), y en los Discursos medicinales de Juan Méndez Nieto, fechados hacia 1606-1611 (arde verde por seco y justo por pecador). A falta de un estudio de mayor profundidad, no debería descartarse la posibilidad de que en su origen la paremia fuera una estructura bimembre que terminó simplificándose, por lo que: /arder [verde por seco] y (pagar / lazrar, etc.) justo por pecador/ > /(arder, pagar, lastrar) justo por pecador/, junto a sus variantes en singular y plural. 
La búsqueda en la base de datos CORDE ofrece un panorama ilustrativo acerca de la pervivencia de esta paremia en los textos que abarcan desde la Edad Media hasta el siglo XVIII. En dicho segmento temporal, se documentan cinco casos para la variante en singular / justo por pecador/, que contrastan con los 51 documentos para /justos por pecadores/ y los cuatro (entre el siglo XV y XIX) de/los justos por pecadores/.

La abrumadora diferencia no resulta casual, en tanto un análisis métrico de estas estructuras confirma mayor regularidad para la variante plural, ya que pecadores confiere a la paremia un dáctilo llano, frente al dáctilo agudo más inestable de pecador:

\begin{tabular}{|l|l|}
\hline \multicolumn{1}{|c|}{ Variantes de la paremia } & Escansión métrica \\
\hline Justos por pecadores & óo óo oóo \\
Los justos por los pecadores & oóo óo óo óo \\
Justo por pecador & óo óo oó \\
El justo por el pecador & oóo oó ooó \\
\hline
\end{tabular}

La elección de la forma plural por parte de Juan Ruiz encuentra explicación desde la perspectiva métrica, ya que el ritmo regular de /A las vegadas lastran justos por pecadores/ (óo oóo óo / óo óo oóo) se inserta perfectamente en un verso alejandrino formado por hemistiquios heptasílabos, frente a la variante que presenta mayor inestabilidad en la obra prosística promovida por Alfonso Onceno ${ }^{35}$.

\subsection{Isorritmia, isometría y rima}

3.2.1. El ritmo acentual de /muy loco es a quien el loco tresquilal viene marcado por la anacrusis y la consecución de cuatro troqueos y un dáctilo; la variante de base octosílaba que ofrecen $M a$ y $M^{\prime}$, por el contrario, se caracteriza por cuatro troqueos a los que antecede un período de anacrusis. Ambos casos, que no encuentran documentación en bases de datos como el CORDE o en CNDHE (Corpus del Nuevo Diccionario Histórico del Españo ${ }^{36}$ ), se caracterizan por una regularidad rítmica que justifica su alto grado de fijeza en la lengua:

\begin{tabular}{|l|l|}
\hline \multicolumn{1}{|c|}{ Crónica troyana } & Escansión métrica \\
\hline Muy loco es a quien el loco tresquila $($ p. 1327) & [o] óo óo óo óo oóo \\
\hline Muy fol es quien el fol tresquila $\left(\right.$ Ma y $\left.M^{\prime}\right)$ & {$[$ o] óo óo óo óo } \\
\hline
\end{tabular}

${ }^{35}$ El uso de la paremia en plural aumenta progresivamente, en tanto decae la variante en singular, como así es de esperar desde una perspectiva isorrítmica.

${ }^{36}$ CNDHE, en línea: <http://web.frl.es/CNDHE/view/inicioExterno.view;jsessionid=9C6 100BCE45B655C05182CAF0E4FB8E3> [consulta: 30/01/2018]. 
3.2.2. La paremia /de los escarmentados se fazen los arteros/ la registra la Crónica troyana sin variación alguna, en tanto su alto grado de fijeza queda justificado por la perfecta isorritmia, e incluso isometría, que presentan los dos miembros heptasílabos trocaicos que conforman este «proverbio antigo», documentado por vez primera en la Historia troyana polimétrica: /De los escarmentados se fazen los arteros/ (p. 428, [o] óo óo óo / [o] óo óo óo).

\begin{tabular}{|c|c|c|}
\hline Datación & Paremia & Escansión métrica \\
\hline c. 1270 & $\begin{array}{l}\text { «de los escarmentados se fazen los arteros» (Historia } \\
\text { troyana polimétrica, p. 239) }\end{array}$ & $\begin{array}{l}\text { [o] óo óo óo / } \\
\text { [o] óo óo óo }\end{array}$ \\
\hline c. 1300 & $\begin{array}{l}\text { ¿No sabes tú que de los escarmentados salen los } \\
\text { arteros? (Libro del cavallero Çifar, fol. } 49 \mathrm{v} \text { ) }\end{array}$ & $\begin{array}{l}\text { [o] óo óo óo / } \\
\text { óo óo óo }\end{array}$ \\
\hline 1450 & $\begin{array}{l}\text { 104. De los escarmentados se leuantan los arteros } \\
\text { (Seniloquium) }\end{array}$ & $\begin{array}{l}\text { [o] óo óo óo / } \\
\text { [o] oóo óo óo }\end{array}$ \\
\hline 1534 & $\begin{array}{l}\text { de los escarmentados se hazen los arteros (Feliciano } \\
\text { de Silva, Segunda Celestina) }\end{array}$ & $\begin{array}{l}\text { [o] óo óo óo / } \\
\text { [o] óo óo óo }\end{array}$ \\
\hline 1535 & $\begin{array}{l}\text { «De los escarmentados se levantan los arteros }{ }^{37} \\
\text { (Juan de Valdés, Diálogo de la lengua) }\end{array}$ & $\begin{array}{l}\text { [o] óo óo óo / } \\
\text { [o] oóo óo óo }\end{array}$ \\
\hline 1555 & $\begin{array}{l}\text { De los escarmentados se levantan los arteros } \\
\text { (Hernán Núñez, Refranes o proverbios en romance) }\end{array}$ & $\begin{array}{l}\text { [o] óo óo óo / } \\
\text { [o] oóo óo óo }\end{array}$ \\
\hline 1602 & $\begin{array}{l}\text { de los escarmentados salen los arteros (Mateo } \\
\text { Alemán, Segunda parte de la vida del pícaro } \\
\text { Guzmán de Alfarache) }\end{array}$ & $\begin{array}{l}\text { [o] óo óo óo / } \\
\text { óo óo óo }\end{array}$ \\
\hline 1632 & $\begin{array}{l}\text { de los escarmentados se hacen }{ }^{38} \text { los arteros (Alonso } \\
\text { de Castillo Solórzano, La niña de los embustes) }\end{array}$ & $\begin{array}{l}\text { [o] óo óo óo / } \\
\text { óo óo óo }\end{array}$ \\
\hline
\end{tabular}

La obra de Valdés constituye punto de inflexión en el uso de esta paremia con la forma levantar en su segundo miembro, en tanto desde 1535 hasta 1600 es la forma preferida. A partir de 1600 se recupera la variante con el verbo $<$ salir $>$ hasta que en 1632 parece haberse consolidado la variante con $<$ hacer $>$.

En el proceso evolutivo que abarca /de los escarmentados se fazen los arteros/, en que $<\mathrm{f}>\mathrm{o}<\mathrm{h}>$ tenían valor fónico ([o] óo óo óo / [o] óo óo óo; o incluso oóo óo óo / oóo óo óo), a la variante con sinalefa /de los escarmentados se hacen los arteros/ ([o] óo óo óo / óo óo óo), si aplicamos anacrusis, la estructura rítmica resultante no varía de su primigenia. Por el contrario, no resultaría del todo imposible pensar que la carencia de isorritmia de la paremia resultante -sin anacrusis, oóo óo óo / óo óo óo-, motivara la génesis de una variante sinonímica

${ }^{37}$ El apunte lingüístico que proporciona Valdés en su Diálogo de la lengua es de relevancia para el estudio métrico de esta paremia: «[...] si el vocablo que precede acaba en $e$, no la pongo en el que sigue; y assí digo: Casa de sgremidores, [...] y si el vocablo precedente no acaba en $e$, póngola en el que sigue, y assí digo: 'De los escarmentados se levantan los arteros' [...] Pésame que no se use artero, porque, como veis, es buen vocablo, y sta usado entre los refranes; uno dize: 'A escasso señor, artero servidor', y otro: 'De los escarmentados se levantan los arteros'».

${ }^{38}$ Ya en época de Alonso de Castillo Solórzano, la grafía $<\mathrm{h}>$ no tendría valor fónico, por lo que la sinalefa con la voz anterior es obligatoria. 
que recuperó el isosilabismo inicial: /de los escarmentados nacen los avisados/ (oóo óo óo / óoo óo óo), documentada por vez primera en 1876-1880 en El Bandolerismo. Estudio social y memorias históricas de Zugasti y Sáenz, actualmente en desuso.

3.2.3. La Crónica troyana constata la documentación de paremias isométricas con presencia de rima; es el caso de /Cabra va por viña, cual fizo la madre, tal fizo la fija/ (p. 1491, óo óo óo / oóo oóo / oóo oóo).

La motivación de esta paremia, de larga trayectoria histórica, encuentra fundamento en el ámbito de los bajos fondos populares, o incluso en el de la prostitución, como así lo manifiesta el propio Covarrubias en 1611 ( $s . v$. CABRA): «la ruin madre, con su ejemplo, es causa que su hija siguiendo sus pisadas sea mala».

\begin{tabular}{|c|c|c|}
\hline Datación & Variante de la paremia & Escansión métrica \\
\hline c. 1350 & $\begin{array}{l}\text { Cabra va por viña, cual fizo la madre, tal fizo la fija } \\
\text { (Crónica troyana, p. 1491) }\end{array}$ & $\begin{array}{l}\text { óo óo óo / oóo oóo / } \\
\text { oóo oóo }\end{array}$ \\
\hline c. 1454 & $\begin{array}{l}\text { 164. Cabra va por viña, qual madre tal fija } \\
\text { (Marqués de Santillana, Refranes que dizen las } \\
\text { viejas tras el fuego) }\end{array}$ & óo óo óo / oóo / oóo \\
\hline 1528 & $\begin{array}{l}\text { cual la madre, tal la hija (Juan Justiniano, } \\
\text { Instrucción de la mujer cristiana, de J. L. Vives) }\end{array}$ & óo óo / óo óo \\
\hline 1555 & $\begin{array}{l}\text { Cabra va por viña, cual la madre, tal la hija } \\
\text { (Hernán Núñez, Refranes o proverbios en romance) }\end{array}$ & $\begin{array}{l}\text { óo óo óo / óo óo / } \\
\text { óo óo }\end{array}$ \\
\hline 1555 & $\begin{array}{l}\text { A cabra vay por viña, por do vay a madre, vay a } \\
\text { filla (Hernán Núñez, Repertorio gallego-portugués } \\
\text { del refranero del comendador Hernán Núñez }{ }^{39} \text { ) }\end{array}$ & $\begin{array}{l}\text { oóo óo óo / óo óo óo } \\
\text { / óo óo }\end{array}$ \\
\hline 1568 & $\begin{array}{l}\text { Cabra va por viña; qual la madre, tal la hija (Juan } \\
\text { de Mal Lara, Philosophia vulgar) }\end{array}$ & $\begin{array}{l}\text { óo óo óo / óo óo / } \\
\text { óo óo }\end{array}$ \\
\hline 1589 & $\begin{array}{l}\text { cual la madre, tal la hija (Juan de Pineda, Diálogos } \\
\text { familiares de la agricultura cristiana) }\end{array}$ & óo óo / óo óo \\
\hline 1611 & $\begin{array}{l}\text { Por do salta la cabra salta la que la mama } \\
\text { (Sebastián de Covarrubias, Tesoro de la lengua } \\
\text { castellana o española) }\end{array}$ & $\begin{array}{l}\text { óo óo oóo / } \\
\text { óo óo oóo }\end{array}$ \\
\hline 1627 & $\begin{array}{l}\text { Cabra (va) por viña, cual la madre, tal la hija } \\
\text { (Gonzalo Correas, Vocabulario de refranes) }\end{array}$ & $\begin{array}{l}\text { óo oóo (óo óo óo) / } \\
\text { óo óo / óo óo }\end{array}$ \\
\hline 1745 & $\begin{array}{l}\text { Cabra va por viña, tal madre, tal hija (Fray } \\
\text { Sarmiento, Memorias para la Historia de la poesía } \\
\text { y poetas españoles, p. 175) }\end{array}$ & óo óo óo / oóo / oóo \\
\hline
\end{tabular}

La estructura gramatical comparativa subyacente del tipo [cual A à $t a l \mathrm{~B}] \mathrm{o}$ [de $\mathrm{A}$ à $t a l \mathrm{~B}]$ fue muy productiva en el proceso de generación variacional, como es el caso de /cual la madre, tal la hija/, forma reducida isométrica (óo óo / óo óo) procedente, a todas luces, de

${ }^{39}$ Anónimo, El repertorio gallego-portugués del refranero del comendador Hernán Núñez, Santiago Alfonso López Navia (ed.), Filología Románica, 5 (1987-1988), pp. 125-182. 
/Cabra va por viña, cual fizo la madre, tal fizo la fija ${ }^{40}$, que perduró en la lengua a lo largo del siglo XVI.

La elisión de los núcleos del segundo miembro, que apenas aportan contenido semántico, permite un reajuste rítmico en pies métricos trocaicos, a semejanza del primer miembro, por lo que la forma recogida por Núñez, Mal Lara y Correas, se caracteriza por una regularidad rítmica (óo óo óo / óo óo / óo óo) que justifica su perduración a lo largo del tiempo.

No es de extrañar que, en el siglo XVIII, Fray Martín Sarmiento ${ }^{41}$ estudiara las paremias como estructuras versales o género de versos, caracterizados a su vez por estructuras fónico-melódicas propias de la lengua natural. En este caso, la elección de la variante que mejor se adapta a sus preceptos teóricos es la de un verso dodecasílabo dividido en dos hemistiquios hexasílabos (óo óo óo / oóo oóo), a semejanza de la obra del Marqués de Santillana. Sarmiento prefiere recoger una forma anclada en el imaginario popular que parece no tener correspondencia con otra documentación de su época para enmarcarla en el molde poético del hexasílabo.

3.2.4. La última de las paremias que documenta la Crónica troyana (/faz bien e non cates a quien/, p. 638) se corresponde con el ámbito bíblico. Desde su primera documentación registrada en la Historia troyana polimétrica, /Faz bien e non cates a quien/ se caracteriza por su regularidad isosilábica (oó oó óo oó), en tanto se trata de un esquema octosílabo de ritmo trocaico.

Es precisamente la naturaleza métrica octosílaba de esta paremia el factor que hizo posible su fijación y, por consiguiente, la inexistencia de documentación de otras variantes. En el momento en que el vocablo catar entró en desuso, fue reemplazado por la forma mirar que, a su vez, respetaba el pie métrico trocaico llano originario (óo) de la segunda persona del singular (cates $>$ mires):

\begin{tabular}{|l|l|l|}
\hline Datación & \multicolumn{1}{|c|}{ Variante de la paremia } & Escansión métrica \\
\hline c. 1270 & $\begin{array}{l}\text { faz bien e non cates a quien (Historia troyana } \\
\text { polimétrica) }\end{array}$ & oó oó óo oó \\
\hline c. 1285 & $\begin{array}{l}\text { E faz bien e non cates a quien (Libro de los cien } \\
\text { capitulos) }\end{array}$ & oó oó óo oó \\
\hline 1454 & $\begin{array}{l}\text { 328. Faz bien y no cates a quien (Marqués de } \\
\text { Santillana, Refranes que dizen las viejas tras el fuego) }\end{array}$ & oó oó óo oó \\
\hline 1541 & $\begin{array}{l}\text { Haz bien: y no cates a quien (La glosa de 1541 a los } \\
\text { refranes que dizen las viejas tras el fuego) }\end{array}$ & oó oó óo oó \\
\hline
\end{tabular}

${ }^{40}$ Variante en desuso conservada hoy día que comparte campo semántico es /Cabra (va) por viña, peor es que tiña/ que, a su vez, también se caracteriza por su regularidad rítmica (óo oóo / oó oóo // óo óo óo / oó óo óo).

${ }^{41}$ Fray Martín Sarmiento, Memorias para la historia de la poesia, y poetas españoles, Madrid, D. Joachin Ibarra Impresor de Cámara de S. M., 1775 (<https://books.google.es/>). En otro momento dedicaré un estudio en torno a la obra del padre Sarmiento. 


\begin{tabular}{|l|l|l|}
\hline 1589 & $\begin{array}{l}\text { haz bien y no cates a quien (Juan de Pineda, Diálogos } \\
\text { familiares de la agricultura cristiana, 23) }\end{array}$ & oó oó óo oó \\
\hline 1627 & $\begin{array}{l}\text { Kon letras de oro avía de estar eskrito este rrefrán } \\
{[\ldots] \text { ke no le é visto en otra lengua, haz bien i no }} \\
\text { kates a kien (Gonzalo Correas, Vocabulario de } \\
\text { refranes y frases proverbiales) }\end{array}$ & oó oó \\
\hline 1657 & $\begin{array}{l}\text { Haz bien y no mires a quién; antes, se ha de mirar } \\
\text { mucho a quien no sea el ingrato (Baltasar Gracián, } \\
\text { El Criticón, 1657) }\end{array}$ & oó oó óo oó \\
\hline
\end{tabular}

La popularidad alcanzada de este refrán hizo posible la circulación de variantes originadas por un proceso de desautomatización con claros fines pragmáticos:

\begin{tabular}{|l|l|l|}
\hline Datación & \multicolumn{1}{|c|}{ Variante de la paremia } & Escansión métrica \\
\hline 1614 & $\begin{array}{l}\text { haz mal y no cates a quién, haz bien y guárdate } \\
\text { (Alonso Fernández de Avellaneda, Don Quijote de } \\
\text { la Mancha, III, 14) }\end{array}$ & $\begin{array}{l}\text { oó oó óo oó // } \\
\text { oó oóo] }\end{array}$ \\
\hline 1627 & $\begin{array}{l}\text { La otra parte: haz mal, i guarte [...]. Algunos, } \\
\text { eskarmentados, truekan las palavras, i dizen: Haz Ha } \\
\text { mal, i no kates a kien; haz bien, i guarte; }[\ldots] \text { la otra } \\
\text { parte, haz bien i guarte, se dize kon eskarmiento i } \\
\text { aviso (Gonzalo Correas, Vocabulario de refranes y } \\
\text { frases proverbiales, } \text { p. 582) }\end{array}$ & // \\
oó oó óo oó oóo \\
\hline 1870 & $\begin{array}{l}\text { haz bien y espera mal (Lucio Victorio Mansilla, Una } \\
\text { excursión a los indios Ranqueles, Argentina, p. 286) }\end{array}$ & oó oó oó \\
\hline 1928 & $\begin{array}{l}\text { haz bien sin mirar a quien (Hermilio Alcalde del Río, } \\
\text { Escenas cántabras (apuntes del natural), Segunda } \\
\text { serie, p. 235) }\end{array}$ & oó oó oó \\
\hline
\end{tabular}

Sin embargo, no todas estas variantes llegaron a constituirse como refranes potencialmente funcionales para asentarse en el paradigma de la lengua. La forma /haz bien sin mirar a quien/, registrada por Hermilio Alcalde del Río, es documentación exclusiva en las bases de datos del CORDE y CREA; sin embargo, no parece casual que Ricardo Parma, escritor de Lima, titulara uno de sus cuentos de carácter costumbrista «Haz bien sin mirar a quien», recogido en Tradiciones peruanas (1872). La modificación de la paremia podría haber recorrido un viaje de ida y vuelta en el marco del creacionismo literario.

De otro modo, la variante /haz bien y espera mal/ no incurre en ninguna irregularidad rítmica, ya que sus constituyentes conforman un hexasílabo de ritmo trocaico; en cambio, su ámbito de uso parece restringirse al de la creación literaria o incluso al de la creación individual, en tanto no aparece en ninguna otra base de datos. 


\section{CONCLUSIONES}

Cada paremia tiene su historia, y si es importante estudiar cada una de ellas en su contexto histórico-filológico, no lo es menos indagar en ciertos patrones constitutivos que han operado en la evolución y posterior acomodación de estas estructuras complejas. En este sentido, el ritmo y la métrica se erigen como constituyentes esenciales, aunque no exclusivos, de la evolución paremiológica, entendida como parte de una teoría fraseométrica. A pesar de que muchos refranes no han mantenido una forma isosilábica con rima interna, sí parece haberse establecido una suerte de isorritmia generalizada que ha permitido su pervivencia a lo largo de la historia, y que los ha diferenciado de sentencias o adagios, entre otras estructuras.

Tomando como base las paremias documentadas en la Crónica troyana ordenada por Alfonso Onceno, se ha constatado la presencia de paremias fluctuantes en proceso de fijación que han ido adquiriendo una estructura rítmico-silábica más estable:

\begin{tabular}{|c|c|}
\hline Paremias en proceso de fijación & Escansión métrica \\
\hline $\begin{array}{l}\text { Me entra por la una oreja e me sale por la otra/>/ } \\
\text { Por una oreja le entra, y por otra le sale/ }\end{array}$ & $\begin{array}{l}\text { óo oó oóo / óo óo óo óo > } \\
\text { oóo óo óo / óo óo oóo }\end{array}$ \\
\hline $\begin{array}{l}\text { /Mal de muchos confuerto es/ - /Mal de muchos gozo } \\
\text { es/> /mal de muchos conorte/consuelo es/ }\end{array}$ & $\begin{array}{l}\text { óo óo / oó oó - óo óo / òoó > } \\
\text { óo óo / oó oó }\end{array}$ \\
\hline $\begin{array}{l}\text { Suele arder el justo por el pecador/ > /(Pagan) } \\
\text { Justos por pecadores/ }\end{array}$ & $\begin{array}{l}\text { óo óo óo / oó ooó }> \\
\text { (óo) óo óo oóo }\end{array}$ \\
\hline
\end{tabular}

Por otro lado, en la Edad Media existían formas isorrítmicas e isométricas, caracterizadas por una rima interna; muchas de ellas han pervivido hasta la actualidad sin experimentar cambios consustanciales en su propia estructura:

\begin{tabular}{|c|c|}
\hline Isorritmia, isometría y rima & Escansión mética \\
\hline /Muy loco es a quien el loco tresquila/ & [o] óo óo óo óo oóo \\
\hline $\begin{array}{l}\text { De los escarmentados se fazen los arteros/> } \\
\text { /De los escarmentados se hacen los arteros/ }\end{array}$ & $\begin{array}{l}\text { [o] óo óo óo / [o] óo óo óo }> \\
\text { [o] óo óo óo / óo óo óo }\end{array}$ \\
\hline $\begin{array}{l}\text { /Cabra va por viña, cual fizo la madre, tal fizo la fija/> } \\
\text { /Cabra va por viña, cual la madre, tal la hija/ }\end{array}$ & $\begin{array}{l}\text { óo óo óo / oóo oóo / oóo oóo }> \\
\text { óo óo óo / óo óo / óo óo }\end{array}$ \\
\hline $\begin{array}{l}\text { /Faz bien e non cates a quien/> } \\
\text { /Haz bien y no mires a quien/ }\end{array}$ & $\begin{array}{l}\text { oó oó óo oó > } \\
\text { oó oó óo oó }\end{array}$ \\
\hline
\end{tabular}

Desde esta perspectiva, el influjo del metro poético y la rima pudieron haber ocasionado la variación de las estructuras lingüísticas todavía en proceso de cambio. Así como el ritmo natural de la lengua castellana fue uno de los factores que influyó en la fijación de las formas lingüísticas y, a su vez, en la evolución del metro poético; en el caso de las paremias, algunas ya plenamente fijadas en la Baja Edad Media, se vieron alteradas, con carácter general, en aras de conformar 
una unidad lingüística compleja caracterizada por un ritmo (y a veces rima) propio y exclusivo de cada una de ellas que les ha conferido vida propia en la andadura del imaginario común colectivo.

Recibido: 30/01/2018

Aceptado: 17/04/2018

\title{
$\cos$
}

\section{LAS PAREMIAS DE LA CRÓNICA TROYANA PROMOVIDA POR ALFONSO ONCENO (1312-1350) EN SU CONTEXTO FILOLÓGICO: INESTABILIDAD, RITMO Y FIJEZA}

\begin{abstract}
RESUMEN: La presente investigación consiste en el estudio de las paremias documentadas en la Crónica troyana promovida por Alfonso Onceno, inserta en la línea genética del Roman de Troie. El análisis filológico de la misma, complementado con descripciones interdisciplinares procedentes de ámbitos como la fonética o la morfología históricas contrastivas, servirá de complemento para enmarcar la obra en su contexto determinado, así como conducirá al examen variacional de los refranes en el marco de una fraseometría histórica.
\end{abstract}

Palabras Clave: Historia de la lengua, fraseometría histórica, fonética, métrica, materia troyana.

\section{THE PROVERBS OF THE CRONICA TROYANA PROMOTED BY ALFONSO ONCENO (1312-1350) IN THEIR PHILOLOGICAL CONTEXT: INSTABILITY, RHYTHM AND FIXITY}

ABSTRACT: The current paper has the aim to research the documented proverbs in the Crónica troyana promoted by Alfonso Onceno, which belongs to the reception of the Roman de Troie. The philological characterization of this text, complemented by historical interdisciplinary theories (contrastive Phonetics, Morphology and Metrics), will allow us to insert the text in its adequate context, as well as to reconstruct the variation of the proverbs in the frame of a historical Phraseometry.

KeYwords: History of Language, Historical Phraseometry, Phonetics, Metrics, Trojan tradition. 